\title{
Limb Body Wall Complex Associated with Placenta Accreta: A Mere Coincidence or a Sign of an Etiopathogenic Link?
}

\section{Limb body wall complex associada à placenta acreta: uma mera coincidência ou um indício de um elo etiopatogênico?}

\author{
Marcos Masaru Okido ${ }^{1}$ Aderson Tadeu Berezowski ${ }^{1}$ Sandra Regina Marques Carvalho ${ }^{1}$ \\ Geraldo Duarte ${ }^{1}$ Ricardo de Carvalho Cavalli ${ }^{1}$ Alessandra Cristina Marcolin ${ }^{1}$ \\ 1 Department of Gynecology and Obstetrics, Hospital das Clínicas, \\ Faculdade de Medicina de Ribeirão Preto, Universidade de São Paulo - \\ USP, Ribeirão Preto, SP, Brazil \\ Rev Bras Ginecol Obstet 2017;39:142-146. \\ Address for correspondence Marcos Masaru Okido, MD, PhD, \\ Department of Gynecology and Obstetrics, Hospital das Clínicas, \\ Faculdade de Medicina de Ribeirão Preto, Universidade de São Paulo, \\ Avenida dos Bandeirantes, 3.900-Monte Alegre, 14049-900-Ribeirão \\ Preto (SP), Brazil (e-mail: mokido@usp.br).
}
Abstract
Keywords
- ultrasonography
- prenatal diagnosis
- limb body wall complex
- placenta accreta
- etiology

A case was reported of a fetus with the anomaly of limb body wall complex associated with placenta accreta. To date, only one account of this condition has been published in the world literature. Due to the low frequency of both complications, the hypothesis has been raised that this association may have happened not by mere coincidence, but rather by a possible common etiopathogenic mechanism. For the first time, a study proposes the existence of a possible etiopathogenic connection between the anomaly of limb body wall complex and hypoxic disorders caused by inadequate placentation in previous uterine scarring.

Foi relatado um caso de feto com anomalia de limb body wall complex associada a uma placenta acreta. Até o presente, apenas uma descrição com essa condição foi publicada na literatura mundial. Devido à baixa frequência das duas complicações, foi levantada a hipótese de que essa associação possa ter ocorrido não por uma mera coincidência, mas por um possível mecanismo etiopatogênico comum. Pela primeira vez, um estudo propõe a existência de uma possível possível ligação etiopatogênica entre a anomalia de limb body wall complex e os transtornos hipóxicos causados pela placentação inadequada em cicatriz uterina prévia.

\section{Introduction}

Limb body wall complex (LBWC) is a lethal congenital anomaly, which is characterized by a spectrum of multiple defects. The most common issues include an extensive thoracoabdominal wall defect associated with deformity of limbs, kypho-

received

September 4, 2016

accepted

December 14, 2016

published online

March 3, 2017
$10.1055 / \mathrm{s}-0037-1598607$. ISSN $0100-7203$. scoliosis, and short or absent umbilical cord. Craniofacial lesions, single umbilical artery, intestinal atresia, and spina bifida have also been observed. ${ }^{1,2}$

Prevalence is variable among studies because of the different criteria used for diagnosis and the high rates of fetal loss during pregnancy. ${ }^{3,4}$ In the first trimester, the diagnosis is
Copyright $\odot 2017$ by Thieme-Revinter

Publicações Ltda, Rio de Janeiro, Brazil
License terms

(요 (1) $\Theta \circledast$ 
confirmed in 1:7,500 pregnancies; ${ }^{5}$ however, at birth, only 0.12 cases in $10,000^{6}$ are identified.

The origin of the LBWC anomaly is not known. The endogenous theory ascribes the defects to an intrinsic disorder of the ectodermal placodes. ${ }^{7}$ Placodes are differentiated areas of the ectoderm whose cells migrate to the neighboring mesoderm during the differentiation process of the embryonic tissues. Failure in this mechanism would lead to dysfunction of the mesoderm, which plays a fundamental role in the lateral folding process of the embryonic disk during the gastrulation period. According to the early amniotic rupture theory, we assumed that this phenomenon would cause the entrapment of the embryo to the mesodermal bands of the coelomic cavity. This would prevent the formation of the umbilical pedicle, and the embryo would be subjected to physical forces responsible for constricting malformations and mutilations. ${ }^{8}$ Finally, according to the vascular disruption theory, fetal defects would be a result of hypoxic-ischemic attacks to susceptible tissues during embryogenesis because of disturbances in the blood supply to the embryo. ${ }^{9-12}$

Placenta accreta is the abnormal invasion of chorionic villi in the basal layer of the decidua and in the underlying myometrium, and it may reach the uterine serosa and contiguous organs. ${ }^{13}$ It is clinically manifested by settings of massive hemorrhage during the attempt to remove the placenta. Its prevalence is of 1:533 pregnancies, ${ }^{14}$ and its main risk factor is a history of cesarean section. ${ }^{15}$

The pathogenesis of placenta accreta is not completely understood either, but it is believed that there is a strong association with the remaining vascularization and decidualization defects in the uterine scarring areas. In subsequent pregnancies, there could be failures in the interaction between maternal tissues and trophoblastic cells. This would cause an exaggerated remodeling of the arcuate and radial arteries, an inadequate expression of some cell receptors, and the excessive release of trophoblast-modulating molecules, such as the vascular endothelial growth factor, due to the low oxygen tension. ${ }^{15-17}$ Therefore, hypoxia would stimulate trophoblast proliferation, whereas normoxia would have an inhibitory effect. With the myometrium devoid of decidua, the trophoblastic advance is even more aggressive, because the inhibitory properties fostered by the metalloproteinases of the deciduous extracellular matrix are lost.

In this report, an anomaly case was presented associating the LBWC with placenta accreta. To date, only one account of this association has been published in the world literature. ${ }^{18}$ Judging from the low frequency of both complications, the hypothesis has been raised that this association may have occurred due to a possible etiopathogenic mechanism, and not by mere coincidence. For the first time, a study proposes the existence of a possible etiopathogenic connection between placenta accreta and the LBWC anomaly.

\section{Case}

A pregnant woman, 27 years old, with a history of four cesarean sections, was followed-up at the high risk prenatal clinic of the Clinics Hospital of Faculdade de Medicina de Ribeirão Preto, Universidade de São Paulo, at 31 weeks and 2 days, having been referred due to a fetus with multiple malformations. The 32-week ultrasonography showed a fetus weighing $1,300 \mathrm{~g}$ and an extensive defect of the anterior abdominal wall, severe kyphoscoliosis, and lower limbs offset from the fetal trunk axis. Liver and intestinal loops were observed outside the abdominal cavity in close contact with the placenta (-Figs. 1A and 1B) and short umbilical cord (-Fig. 2). A fetal echocardiography showed the heart displaced downward, toward the abdomen, double output from the right ventricle, and intraventricular muscle communication.

The placental evaluation revealed central (total) placenta previa, with predominant insertion in the anterior segment of the uterus. At this location, the placenta was thick, full of vascular voids, and no myometrial layer was observed
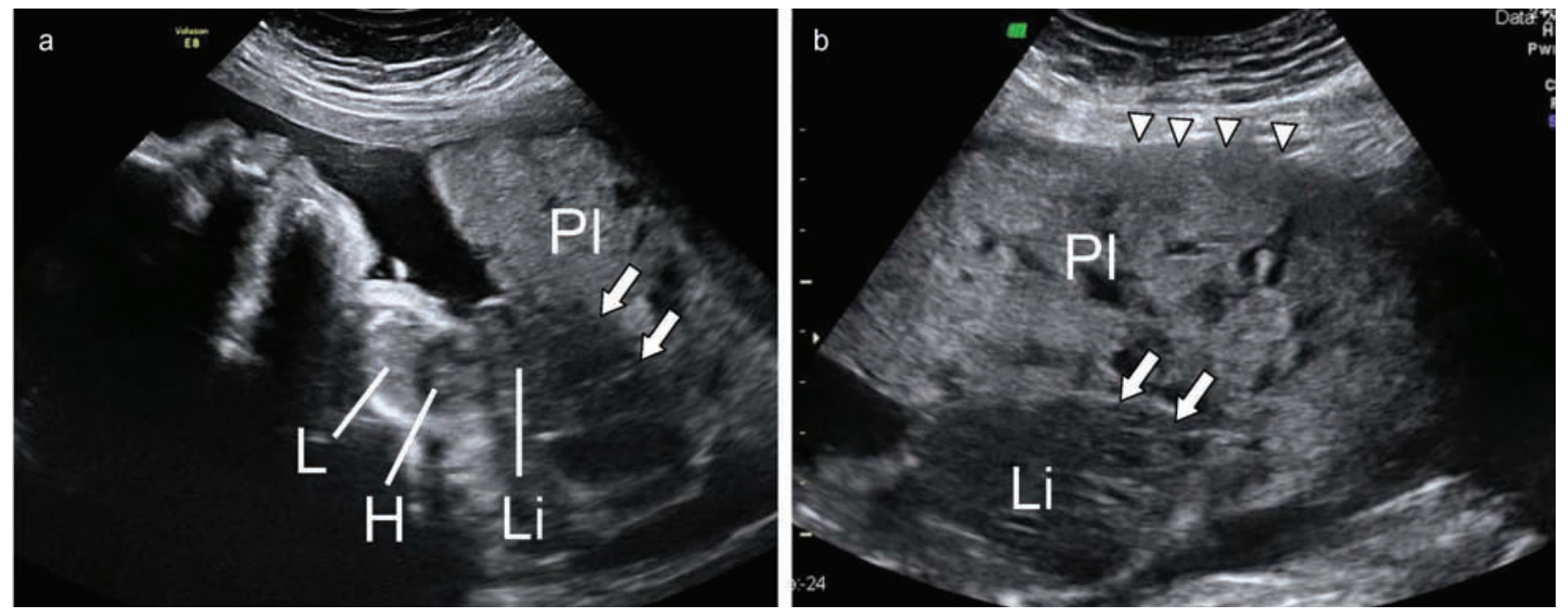

Fig. 1 Ultrasound image at 32 weeks. (a) Fetus in longitudinal view showing extensive abdominal wall defect, heart moved to the caudal position, and liver in contact with the placenta (arrows). (b) Placenta in the segmental region showing several vascular voids and loss of the myometrial layer (arrowheads). One can also see the fetal liver near the placenta (arrows). Abbreviations: PL, placenta; L, Lung; H, heart; Li, liver. 


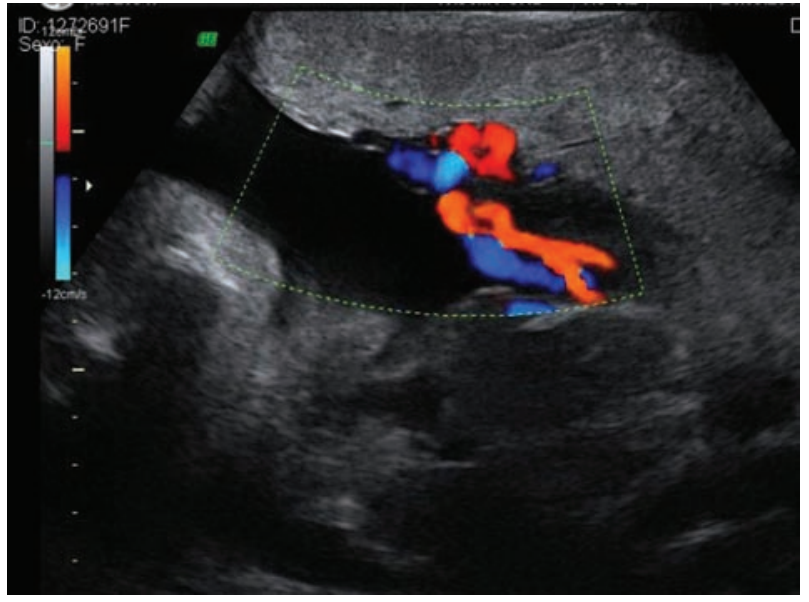

Fig. 2 Ultrasound image at 32 weeks. Observe short umbilical cord.

(-Fig. 1B). The conclusion of this exam was: 32-week topical gestation, limb body wall complex anomaly, total central placenta previa, and placenta accreta. Magnetic resonance imaging (MRI) confirmed the ultrasonography findings (-Fig. 3).

The pregnancy was interrupted at 33 weeks and 6 days. A cesarean delivery was performed followed by a hysterectomy with placenta in situ. Previous to the hysterectomy, an embolization of the internal iliac arteries was performed. The newborn weighed $1,900 \mathrm{~g}$, with undefined sex. It died within a few minutes of life. A large thoracoabdominal defect on the right side and amelia of the ipsilateral upper limb was observed (-Fig. 4). The eventration of the abdominal organs with the placenta confirmed the non-obliteration of

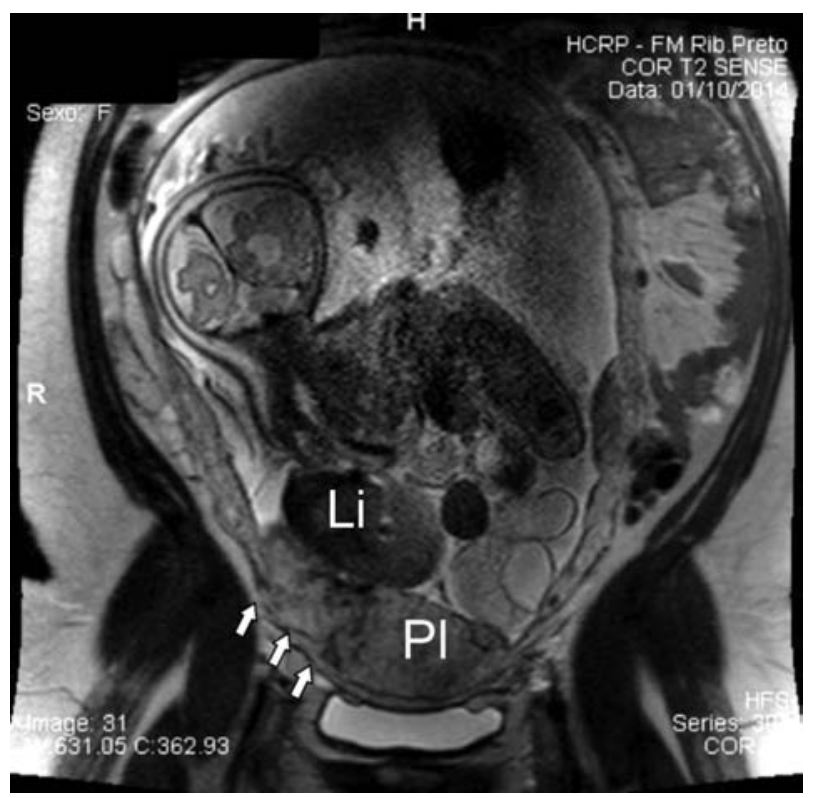

Fig. 3 Fetal MRI image showing severe kyphoscoliosis, liver and intestinal loops out of the abdominal cavity and placenta previa with irregular boundaries with the underlying myometrium (arrows). Abbreviations: PL, placenta; Li, liver.

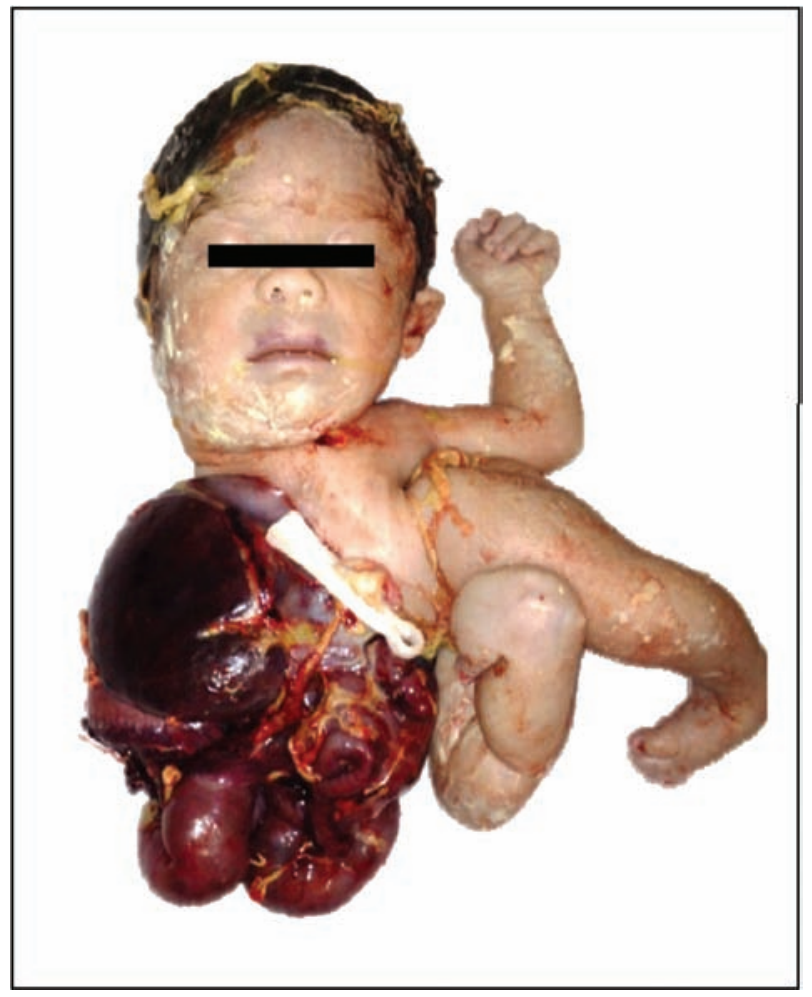

Fig. 4 Newborn photo showing extensive thoracoabdominal defect, serious spine and lower limb tortuosity. Amelia of right upper limb was also observed.

the extraembryonic coelomic cavity. The umbilical cord was observed, albeit short. The amniotic bands were not observed. The genetic examination ruled out other malformations such as the omphalocele-exstrophy-imperforate anusspinal defects (OEIS) complex associated with meningomyelocele. In the anatomopathological exam of the surgical specimen, a third-trimester gestational placenta was observed infiltrating the myometrium by two-thirds of its thickness, with a final report diagnosing placenta increta. The histopathological examination of the placenta showed no mosaicism that could be a cause of placental insufficiency.

\section{Discussion}

The cause of the LBWC malformation is unknown, and although some theories attempt to explain its origin, little has been proven. We believe that the association observed in this case could create a new perspective for the vascular disruption theory. It has been proposed that fetal malformations may have been caused by hypoxic-ischemic mechanisms arising from the failure of the trophoblast to supply the embryo's oxygen demands. Since the abnormal trophoblast invasion of placenta accreta has an essentially hypoxic nature, the poor perfusion of the decidua underlying the trophoblast implantation bed was thought to have led not only to the process of improper invasion, but also to ischemia of the embryo's tissues at critical moments of its development.

The descriptive character of this study does not allow us to affirm that there is a causal relationship between poor 
decidua perfusion and the LBWC malformation; however, some aspects discussed below are worth highlighting.

A key point in the discussion lies in the well-known association between placenta accreta and the presence of prior uterine scarring. If the hypothesis that proposes a pathogenic link between the LBWC and placenta accreta is true, a higher incidence of LBWC cases in women with uterine scarring would have to be proven, since placenta accreta is more frequent in women with this risk factor. So far, this association cannot be proven or ruled out because studies addressing this question have not been published. Another similar type of reasoning could assume that the prevalence of LBWC should be much higher, since cesarean section is a very common surgery. However, it is very likely that other factors must act synergistically, in addition to the poor perfusion of the uterine scar, for embryonic lesions to occur. Probably, in the vast majority of cases, control mechanisms would act on trophoblastic circulation to promptly restore the gas exchange balance and ensure the embryo's normal development. However, in some situations of serious vascular disruption, where the reduction in blood flow is abrupt and intense, there would be no time for such balance to take place, and hypoxia, in these cases, would be severe enough to cause damages to the embryo.

Some literature data show evidence that the association between prior uterine scarring and the LBWC may be true.

An epidemiological aspect to be considered relates to the prevalence of this complication in countries with high rates of caesarean section because, if the association between the LBWC and uterine scarring is true, the prevalence of this malformation should be greater in those populations, as is the case with placenta accreta. In this respect, a study performed in Brazil, where the rates of cesarean section are the world's highest, shows a relevant result. In one reference center, the LBWC cases were evaluated through established diagnostic criteria such as abdominal defect, kyphoscoliosis, and rudimentary umbilical cord. With an average of 2,800 births a year, 21 cases were found in 11 years, representing a prevalence of 1 case for every 1,810 births. ${ }^{4}$ There is no data about the type of prior childbirth that women in the study had undergone; however, this prevalence, even considering the fact that the study was conducted at a reference center, is much higher than that observed in any other study ever published.

Another epidemiological fact that could suggest the association of LBWC and previous cesarean scarring would be an increased incidence over the years, since there has been an increase in cesarean sections in almost all countries. There are no studies seeking to specifically address this issue; however, a study conducted in Denmark shows that this fact may be true. In that country's birth records in 20 years, from 1970 to 1974, only 1 case was reported; from 1975 to 1979 and from 1980 to 1984,4 cases; and from 1985 to 1989,7 cases, without an increase in birth rates. ${ }^{3}$

It is also important to mention that some publications have associated LBWC malformations with other conditions of potential hypoxic risk to the embryo, such as the use of cocaine and multiple pregnancies. Cocaine, for its abrupt and severe vasoconstrictive action, was considered responsible for the LBWC anomaly in women who used the substance in the first trimester in two case reports. ${ }^{19,20}$ On the other hand, the LBWC anomaly in twin pregnancies has been reported in various publications, including cases of a single twin affected in monochorionic pregnancies, which contradicts the hypothesis of the endogenous origin. ${ }^{1,2,21-25}$ It is possible that the rapid growth of embryos can be accompanied by episodes of inadequate perfusion of parts of the trophoblast.

We concluded that multiple factors must be involved in the pathogenesis of the LBWC malformation; however, the association with placenta accreta, observed in this case, shows that the vascular mechanism can be considered one of its main causes. The complex interaction of factors such as the extension of the poorly perfused trophoblast, the timing of onset, and the duration and intensity of the exposure to hypoxia can be determining factors for the genesis of placenta accreta, LBWC malformation or both. The association with placenta accreta points to a possible role of uterine scarring in the etiopathogenesis of the LBWC malformation. This hypothesis is of extreme importance, because it ascribes a risk factor for some fetal malformations to cesarean section birth. Although low, this risk could not be disregarded in a worldwide scenario of increasing rates of cesarean sections. Other studies should be performed to confirm this association.

\section{References}

1 Kähler C, Humbsch K, Schneider U, Seewald HJ. A case report of body stalk anomaly complicating a twin pregnancy. Arch Gynecol Obstet 2003;268(03):245-247

2 Smrcek JM, Germer U, Krokowski M, et al. Prenatal ultrasound diagnosis and management of body stalk anomaly: analysis of nine singleton and two multiple pregnancies. Ultrasound Obstet Gynecol 2003;21(04):322-328

3 Hunter AGW, Seaver LH, Stevenson RE. Limb-body wall defect. Is there a defensible hypothesis and can it explain all the associated anomalies? Am J Med Genet A 2011;155A(09):2045-2059

4 Costa MLB, Couto E, Furlan E, et al. Body stalk anomaly: adverse maternal outcomes in a series of 21 cases. Prenat Diagn 2012; 32(03):264-267

5 Daskalakis G, Sebire NJ, Jurkovic D, Snijders RJM, Nicolaides KH. Body stalk anomaly at 10-14 weeks of gestation. Ultrasound Obstet Gynecol 1997;10(06):416-418

6 Bugge M. Body stalk anomaly in Denmark during 20 years (19701989). Am J Med Genet A 2012;158A(07):1702-1708

7 Streeter GL. Focal deficiency in fetal tissues and their relation to intra-uterine amputation. Contrib Embryol 1930;22(126):33-41

8 Torpin R. Amniochorionic mesoblastic fibrous strings and amnionic bands: associated constricting fetal malformations or fetal death. Am J Obstet Gynecol 1965;91(01):65-75

9 Van Allen MI. Fetal vascular disruptions: mechanisms and some resulting birth defects. Pediatr Ann 1981;10(06):219-233

10 Sahinoglu Z, Uludogan M, Arik H, et al. Prenatal ultrasonographical features of limb body wall complex: a review of etiopathogenesis and a new classification. Fetal Pediatr Pathol 2007;26(03): 135-151

11 Halder A. Amniotic band syndrome and/or limb body wall complex: split or lump. Appl Clin Genet 2010;3:7-15

12 Colpaert C, Bogers J, Hertveldt K, Loquet P, Dumon J, Willems P. Limb-body wall complex: 4 new cases illustrating the importance 
of examining placenta and umbilical cord. Pathol Res Pract 2000; 196(11):783-790

13 Bowman ZS, Eller AG, Kennedy AM, et al. Accuracy of ultrasound for the prediction of placenta accreta. Am J Obstet Gynecol 2014; 211(02):177.e1-177.e7

$14 \mathrm{Wu} \mathrm{S}$, Kocherginsky M, Hibbard JU. Abnormal placentation: twenty-year analysis. Am J Obstet Gynecol 2005;192(05): 1458-1461

15 Jauniaux E, Jurkovic D. Placenta accreta: pathogenesis of a 20th century iatrogenic uterine disease. Placenta 2012;33(04): 244-251

16 Tantbirojn P, Crum CP, Parast MM. Pathophysiology of placenta creta: the role of decidua and extravillous trophoblast. Placenta 2008;29(07):639-645

17 Wehrum MJ, Buhimschi IA, Salafia C, et al. Accreta complicating complete placenta previa is characterized by reduced systemic levels of vascular endothelial growth factor and by epithelial-tomesenchymal transition of the invasive trophoblast. Am J Obstet Gynecol 2011;204(05):411.e1-411.e11

18 Saadi H, Sfakianoudis K, Thomas D. Limb body wall complex associated with placenta previa accrete [Internet]. 2007 [cited 2015 Mar 12]. Available from: https://www.sonoworld.com/fetus/ page.aspx?id=2420
19 Martinez JM, Fortuny A, Comas C, et al. Body stalk anomaly associated with maternal cocaine abuse. Prenat Diagn 1994; 14(08):669-672

20 Viscarello RR, Ferguson DD, Nores J, Hobbins JC. Limb-body wall complex associated with cocaine abuse: further evidence of cocaine's teratogenicity. Obstet Gynecol 1992;80(3 Pt 2):523-526

21 Chen CP, Lee MS, Tsai FJ, Huang MC, Chern SR, Wang W. Limb-body wall complex in one fetus of a dizygotic twin pregnancy conceived by egg donation, in vitro fertilization and embryo transfer: prenatal diagnosis and literature review. Taiwan J Obstet Gynecol 2009;48(04):446-450

22 Daskalakis GJ, Nicolaides KH. Monozygotic twins discordant for body stalk anomaly. Ultrasound Obstet Gynecol 2002;20(01): 79-81

23 Rovida PL, Prefumo F, Frusca T, Fichera A. Concordant body stalk anomaly in a monoamniotic twin pregnancy at 9 weeks. Prenat Diagn 2014;34(09):915-916

24 Hiett AK, Devoe LD, Falls DG III, Martin SA. Ultrasound diagnosis of a twin gestation with concordant body stalk anomaly. A case report. J Reprod Med 1992;37(11):944-946

25 Glasser SA, Zaeri NN, Nisenbaum H. Body stalk deformity in a twin pregnancy: case report and review. Md Med J 1993;42(02): $175-178$ 